Disponível em

http://www.anpad.org.br/rac

RAC, Rio de Janeiro, v. 21, n. 5,

pp. 730-742, Setembro/Outubro, 2017

http://dx.doi.org/10.1590/1982-7849rac2017170069

$(c c)$ EY

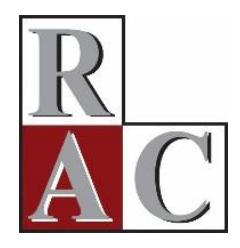

Casos para Ensino:

\title{
Ética e Ensino de Administração: Um Referencial Protestante no Ensino de Administração
}

Ethics and Management Education: A Protestant Reference in Management Education

Éder Júnio de Oliveira ${ }^{1}$ João Paulo Henriques Lopes Silva ${ }^{1}$ Murillo César Barbosa dos Santos ${ }^{1}$

Rodrigo Miranda ${ }^{1}$

Universidade Federal de Uberlândia ${ }^{1}$

Artigo recebido em 23.03.2016. Última versão recebida em 09.12.2016. Aprovado em 16.12.2016. Publicado online em 25.05.2017. Editora Associada: Profa. Anete Alberton 


\section{Contextualização}

Baseado em dados reais e fictícios, o caso a seguir descreve uma situação profissional vivida por Pedro, um jovem executivo que se formou em Administração pela Faculdade Cristã, instituição pertencente ao grupo Comunidade Cristã, que possui a religião e a ética como pilares sustentadores do ensino. Pedro tomou gosto pela área de Recursos Humanos e logo se destacou como diretor de recursos humanos de uma grande confecção de roupas na cidade de Uberlândia. Diante de uma decisão que traria maior competitividade à empresa em detrimento das condições de trabalho e de exploração de indivíduos, Pedro enxergou que os valores, as crenças e a ética do administrador aprendidos na Faculdade estavam em conflito com os interesses do ambiente organizacional no qual estava inserido. Revoltado, Pedro discordou das decisões apresentadas e tentou mudar a direção da empresa, conduzido por sua conduta ética.

\section{O caso}

Qual é a sua decisão, atuar no mercado de forma ilegal para se manter competitivo ou seguir a ética empresarial e a moral religiosa, assumindo os riscos de falência?

A Faculdade Cristã de Ensino Superior (FACES) iniciou suas atividades em 2008 oferecendo inicialmente o curso de Teologia. Analisando a estrutura em que a entidade está inserida, percebe-se que esse curso está fortemente vinculado à doutrina da organização, voltada à evangelização, aos seus preceitos éticos e à vocação missionária religiosa de origem protestante.

Após certo tempo, visando atender às necessidades da comunidade, a faculdade passou a oferecer o curso de Gestão de Recursos Humanos, buscando capacitar os alunos a atuarem no mercado de trabalho sob uma perspectiva crítica quanto à ética do administrador. Os alunos do curso de Gestão de Recursos Humanos são, em sua maioria, membros da comunidade Cristã, e, em alguns casos, por não terem condições de pagar a faculdade, têm o curso financiado pela Igreja e/ou pelos membros da mesma.

Os alunos, no decorrer do curso, são convidados a estagiar e auxiliar nas ONG's que a Igreja mantém, podendo de fato aplicar os conhecimentos adquiridos na sala de aula em empresas do terceiro setor, com foco muito grande na própria comunidade. É importante ressaltar que nem todos os alunos são membros da Igreja, e que há alunos inseridos profissionalmente em grandes empresas de Uberlândia.

A organização tem, na figura de seus fundadores, um casal de missionários norte-americanos. No início dos períodos letivos, um deles vai à faculdade e ministra palestras para todos os alunos. Além disso, os professores são, em sua grande maioria, membros da comunidade Cristã, e levam consigo esse referencial protestante neopentecostal característico da Igreja.

Os professores não são obrigados, mas podem, se quiserem, utilizar materiais como vídeos, documentários e casos religiosos nas aulas para transmitir as matérias relacionadas à Gestão de Recursos Humanos aos alunos. E, apesar dos cursos serem fornecidos de maneira separada, os alunos de Recursos Humanos fazem algumas disciplinas junto com os alunos de teologia (como Ética e Sustentabilidade).

Pedro é membro da comunidade Cristã e estudou Gestão de Recursos Humanos na Faculdade Cristã. É proveniente de uma família muito religiosa, que frequenta a Igreja desde que ele ainda era criança. Teve a oportunidade de estudar desde a infância até a graduação nas escolas da Igreja. Durante a graduação, teve seu curso patrocinado pelos membros da Igreja, com o compromisso de tirar notas boas e participar ativamente dos eventos e projetos que ocorriam tanto na faculdade quanto na Igreja.

Nos últimos períodos de sua graduação, Pedro teve a oportunidade de estagiar na própria comunidade Cristã, auxiliando na gestão dos recursos da Igreja e no desenvolvimento de projetos sociais. Isso foi fundamental para ele se tornar o profissional que é. Através de seu trabalho árduo desenvolvido na comunidade e, logo após formar-se, Pedro foi indicado por um dos membros para trabalhar em uma grande empresa, e, após isso, ele conseguiu se estabelecer no mercado de trabalho. 
Passados alguns anos, Pedro alcançou o cargo de diretor de recursos humanos de uma grande confecção de roupas na cidade de Uberlândia.

A confecção em que Pedro trabalha não possui marca própria e não comercializa no varejo as peças feitas por ela. Essa confecção apresenta um histórico de decisões tomadas baseadas em ética empresarial, confirmando a sólida imagem da empresa, que atua em seu mercado há 50 anos. A ética e a postura de Pedro apresentadas durante o processo seletivo foram determinantes para sua contratação, pois condiziam com os ideais da confecção. A empresa atua como terceirizada de grandes lojas de departamentos nacionais e internacionais que atuam em todo o Brasil. Seu diferencial competitivo encontra-se na estratégia de baixo custo. A mão de obra que a empresa usa é basicamente constituída de homens e mulheres de baixa renda e com pouca instrução. Apesar de ser vantajoso para a empresa que os costureiros tenham experiência prévia, o mesmo não é requerido, pois o ofício pode ser facilmente aprendido.

Após alguns meses se adequando à realidade da empresa, Pedro recebeu um comunicado da cúpula marcando uma reunião urgente com todos os diretores. Afoito em saber do que se tratava, Pedro contou os dias para que chegasse esse momento. No dia da reunião, o jovem diretor foi o primeiro a chegar à sala e se deparou com o dono sentado em sua cadeira, com olhar preocupado. Quando os outros diretores chegaram, o dono da confecção anunciou formalmente o início da reunião:

"Bom dia, caríssimos. Hoje a reunião será sobre um importante tema, e dela serão definidos os rumos que a empresa deve tomar para continuar sendo competitiva e conseguir fechar grandes contratos como conseguíamos antes. Nos últimos anos, nós perdemos sistematicamente vários clientes importantes e os nossos esforços para conseguir grandes contratos estão se mostrando irrelevantes. Quero sugestões para que possamos voltar a conseguir fechar grandes negócios e terminar o ano com saldo positivo, pois, de acordo com o apresentado até o terceiro trimestre deste ano, creio que amargaremos em prejuízo novamente."

Vejam esse gráfico, conforme Figura 1:

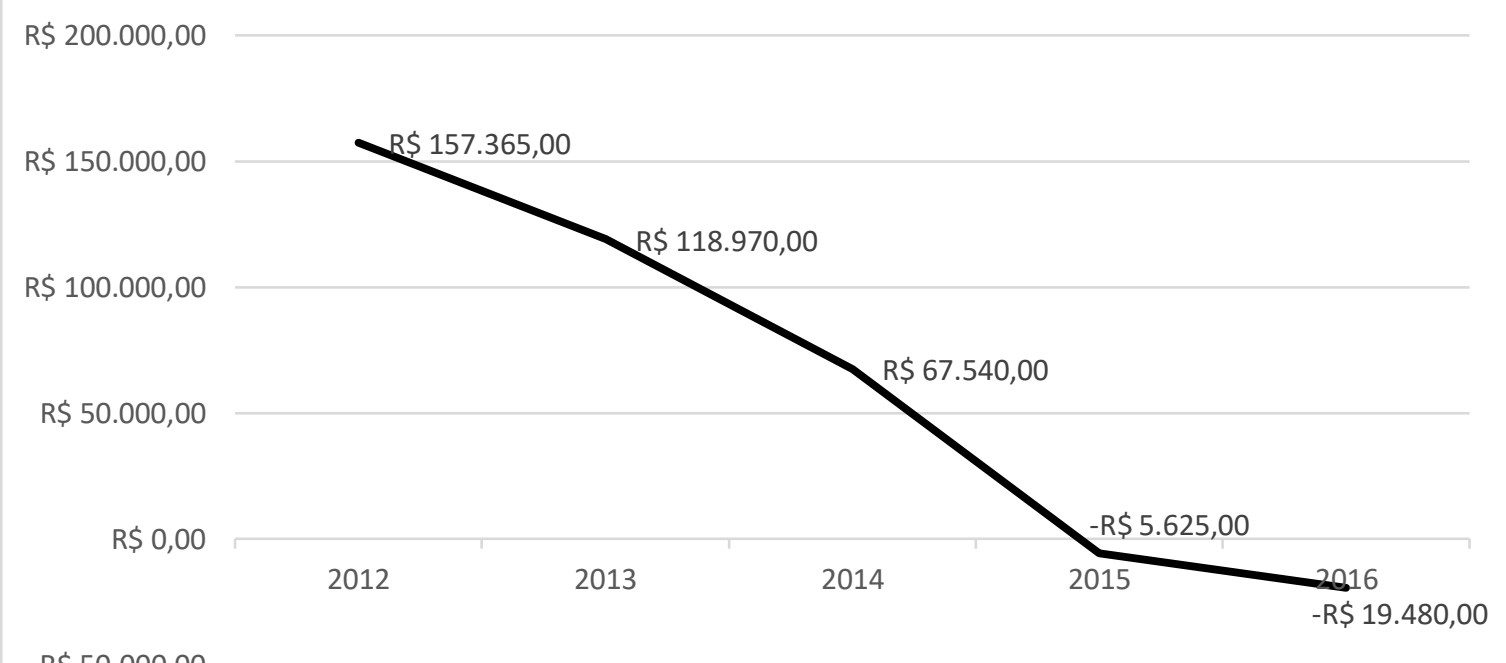

$-R \$ 50.000,00$

Figura 1. Lucro Líquido da Confecção em que Pedro Trabalha

Na Figura 1, o valor de 2016 refere-se ao acumulado até o fim do terceiro trimestre. Os valores estão expressos em milhares de reais. A linha no gráfico representa o comportamento do lucro da confecção ao longo do tempo. Fonte: Elaborado pelos autores.

O diretor de marketing da empresa tomou a palavra para si e disse:

"Senhores, não será necessário que nos esforcemos muito para encontrar os motivos para tais intempéries. No último contrato que perdemos, conversei com os representantes da empresa-cliente e eles me disseram que nossos custos são muito altos, que se continuarmos com nossos preços altos como estão, perderemos todos os contratos." 
A palavra passou para o diretor financeiro da empresa que disse, estupefato:

"Mas como assim preços altos! Estamos trabalhando de maneira mais enxuta possível, temos um alto índice de produtividade por trabalhador temos pouquíssimas perdas de matéria prima. Não há mais de onde cortar custos!"

O diretor de marketing disse:

"Os chineses são nosso principal problema, conseguem entregar as mesmas peças que nós e cobrar menos da metade. Mas eles não são os únicos: há diversas outras confecções que conseguem fazer o que fazemos por não mais que a metade do valor. Foi-se o tempo em que podíamos esbanjar dinheiro com coisas fúteis. Nossas políticas de recursos humanos são obsoletas e deixam os funcionários preguiçosos, remunerandoos com salário fixo."

\section{O diretor de finanças concordou:}

"Realmente nossas despesas com folha de pagamento são altíssimas, muitos impostos, alimentação e convênio médico familiar. Se quisermos voltar a ser competitivos, teremos que fazer o que nossos concorrentes fazem: mudar a forma de remuneração de fixa para variável. Existem empresas concorrentes que pagam $R \$ 0,12$ por peça produzida, enquanto não conseguimos pagar menos que $R \$ 1,10$. O lanche da tarde deverá ser cancelado e ofertado somente ao empregado que conseguir produzir mais que sua própria produção do mês anterior. Teremos que cortar o convênio médico e o plano odontológico também."

\section{O Dono disse:}

"Esse método de fornecimento de lanche não me agrada. Agir dessa forma provocaria falta de materiais em nossas linhas de produção devido ao rápido fluxo de materiais, além de comprometer a gestão de Capital Circulante Líquido e Fluxo de Caixa. Além do mais, cortar tantos benefícios não nos traria problemas judiciais?"

\section{O diretor jurídico disse:}

"Normalmente essas pessoas de baixa renda precisam trabalhar para sustentar seus filhos, e eles não são muito atentos aos aspectos legais. Se a fiscalização nos pegar, teremos muitos problemas, seremos incriminados por mantermos trabalhadores em estado análogo à escravidão e por desrespeitar a CLT. Mas, para evitar isso, nós alugamos um barracão afastado da cidade e colocamos alguns trabalhadores lá, recrutamos alguns em outras cidades e os colocamos morando no barracão, cobramos uma taxa por isso e, depois, pagamos para eles o que eles conseguirem produzir."

\section{O proprietário retrucou:}

"Mas essas decisões são totalmente opostas à ética empresarial. Criamos uma empresa sólida com base na ética e temos considerado essa variável em decisões passadas. Não podemos tomar essa decisão."

\section{O diretor financeiro por sua vez disse:}

"Acredito que seja a única solução, se nossos concorrentes fazem, temos que fazer, isso reduzirá nossos custos em pelo menos $85 \%$, e nos garantirá grandes contratos de novo.... Não nos preocupemos com os trabalhadores, eles ganham muito para fazer tão pouco, e, em tempos difíceis, temos que dançar conforme a música."

Neste momento, o proprietário e os outros apoiaram a decisão, entretanto, Pedro ficou pensativo, lembrou da conduta ética outrora adquirida durante a faculdade e notou que os caminhos escolhidos até o momento eram totalmente contrários à mesma. Dessa forma, Pedro respondeu:

"Isso não pode acontecer! Essa decisão não leva em consideração qualquer preceito ético, temos 50 anos de mercado exercendo nossas atividades na legalidade. Se algum órgão fiscalizador nos descobre seremos obrigados a pagar multas de valores astronômicos! E pior, a imagem de nossa confecção será afetada negativamente, com repercussão em toda a imprensa. E, pior, se isso acontecer, aí é que não fecharemos qualquer contrato. Sou o diretor de Recursos Humanos e não mudo minha postura até chegarmos a um acordo. Como dito anteriormente, essa atitude não faz parte de nossa conduta." 
Depois da fala de Pedro, uma semente de incerteza foi implantada na mente do proprietário e dos demais diretores. É um dilema difícil e, para respondê-lo, a cúpula da empresa resolveu adiar a decisão, com o objetivo de desenvolver novas alternativas para a ideal solução da situação.

\section{Reflexões}

É observado que a religiosidade que permeia o meio de ensino e a vida dos alunos da instituição pode influenciar a conduta profissional e pessoal dos alunos? É possível que esses alunos tenham um referencial ético mais forte, voltado para a ética religiosa protestante e atuem de maneira diferente dos alunos de outras faculdades que não têm essa religiosidade presente no ensino, como outras faculdades particulares e universidades públicas e privadas? 


\title{
Notas de Ensino
}

\section{Resumo}

Este caso para ensino descreve, baseado em fatos reais, a história de Pedro, ex-aluno de Gestão de Recurso Humanos da Faculdade Cristã. A Faculdade é pertencente ao grupo Comunidade Cristã, que há anos atua no setor educacional no município de Uberlândia, Minas Gerais. Pedro optou pela área de Recursos Humanos para construir carreira numa grande confecção de roupas da cidade. Essa confecção não possui marca própria e não comercializa no varejo as peças feitas por ela, entretanto apresenta históricos de decisões baseadas em ética empresarial. Seu objetivo é trabalhar como terceirizada de grandes lojas de departamentos nacionais e internacionais que atuem no Brasil. Seus empregados são homens e mulheres de baixa renda e com pouca instrução. Pressionada pela incapacidade de fechar grandes contratos, a solução encontrada foi a submissão de seus funcionários a condições de trabalho análogas às da escravidão. Pedro, diretor de Recursos Humanos, não concorda com as decisões tomadas até então, pois fogem da conduta ética do administrador. Ao longo da vida, envolvido por suas crenças e preceitos éticos aprendidos na faculdade, Pedro não se conforma, pois decisões dessa dimensão colocam a empresa em um risco maior, podendo acarretar em uma destruição da imagem corporativa e uma desonra à ética empresarial. Sua decisão provoca dúvidas entre os gestores, prorrogando a decisão.

Palavras-chave: ética; religião; valores; negócios; administração.

\begin{abstract}
This teaching case, based on real events, describes the story of Pedro, a former human resource management student at Christian College. The college belongs to a Christian Community that has operated for years in the educational field in the city of Uberlandia, Minas Gerais. Pedro chose human resource management to develop a career in a major clothes company in the city. The company doesn't have its own brand and doesn't sell their own products, but does show a history of ethical business decisions. Its main objective is to work as outsourced manufacturing for major national and international retail department stores that operate in Brazil. Their employees are men and women of low income and limited education. Under pressure from the inability to close large deals the company submitted their workforce to poor working conditions analogous to slave labor. As HR director, Pedro doesn't agree with these measures, since they don't align with management ethics. Throughout his life, based on the beliefs and values learned in college, Pedro refuses to conform, because the decisions place the company at a greater risk that could destroy its corporate image and dishonor corporate ethics. His decision provokes doubts among managers, delaying a final decision.
\end{abstract}

Key words: ethics; religion; values; business; management.

\section{Objetivos educacionais}

- Entender o processo pelo qual uma empresa de confecção de roupas decide utilizar condições análogas às da escravidão, e qual a influência que a ética protestante terá na tomada de decisão.

- Compreender o impacto dos aspectos religiosos no ensino de administração.

- Entender o impacto da religião nos aspectos éticos que envolvem os negócios.

\section{Fonte de obtenção de dados}

Os dados que constituem o respectivo caso para ensino foram coletados por meio de entrevista junto aos coordenadores do curso de Gestão de Recursos Humanos da Faculdade Cristã de Ensino Superior. A entrevista foi realizada na própria faculdade, em novembro de 2014. Também foram 
pesquisadas reportagens (Repórter Brasil, n.d.; Revista de Imprensa Internacional, 2011) que mencionam a ética empresarial e o trabalho escravo na cadeia produtiva da empresa Zara. $\mathrm{O}$ caso foi construído levando em consideração dados reais e acrescido de aspectos fictícios.

\section{Utilização do caso}

O caso é destinado aos alunos dos cursos de Administração e Sociologia. Também pode ser aplicado em disciplinas específicas como: Organizações e Sociedade; Dimensões Antropológicas das Organizações; e Ética em Organizações.

\section{Sugestão para um plano de ensino}

O respectivo caso pode ser analisado em sala de aula tanto em duplas, quanto em grupos de, no mínimo, quatro, e, no máximo, seis alunos. Não é recomendo aplicar o caso individualmente, pois em grupo os alunos irão debater as perguntas entre eles e identificarão valores, princípios éticos e morais que são individuais, mas que, por meio de um debate em grupo, enriquecem o entendimento do caso tanto individual quanto coletivamente.

Para a leitura e a discussão, são necessários 40 minutos. Nos outros 60 minutos, cada grupo apresentará, ao professor e à sala, os pontos mais relevantes da discussão e conclusões às quais chegaram. O intuito dessa parte é promover um debate que envolva todos os alunos, gerando reflexões sobre a influência da ética e da religião nas organizações.

Com o objetivo de alcançar respostas mais realistas e coerentes, faz-se necessária uma leitura prévia dos principais conceitos relacionados à ética nas organizações.

\section{Questões para discussão}

1. É possível notar diferenças entre os objetivos educacionais da faculdade Cristã (confessional) para outras faculdades (laicas) na formação do gestor de recursos humanos?

2. Explique como o acúmulo do capital e o cálculo racional de receitas e despesas incentivam os empresários ao Espírito do Capitalismo?

3. Como os aspectos religiosos influenciam a decisão dos gestores?

4. Qual o papel do gestor de recursos humanos ao trabalhar em uma empresa em que as questões religiosas são profundamente consideradas em sua cultura organizacional?

5. Quando uma empresa contrata uma terceirizada entende-se que a contratante possui total consciência das atividades realizadas pela contratada. Muitas vezes, casos de exploração de empregados nas empresas contratadas são denunciados, e, nessas circunstâncias, surgem dúvidas sobre quem é (são) o (s) responsável (eis) por tais atividades. Quais os motivos levam empresas a contratarem terceirizadas que utilizam trabalho com condições análogas à escravidão em seu processo produtivo?

\section{Breve Revisão de Literatura}

\section{Teoria organizacional e estudos da religião}

Os estudos da religião são considerados clássicos na sociologia moderna. Marx, Weber e Durkheim, vistos como fundadores das ciências sociais, fizeram considerações importantes sobre a religiosidade e sua influência nos grupos sociais. A teoria organizacional recebeu uma grande influência desses autores e de outros que foram capazes de proporcionar um melhor entendimento sobre o 
fenômeno organizacional. No entanto, são poucos os estudos da influência da religião e da religiosidade nas organizações e nos estudos organizacionais. Weber (2004) é amplamente citado como teórico da burocracia, no entanto, seus escritos sobre a ética religiosa se limitam a fazer um contraponto entre as dominações carismáticas e tradicionais com a dominação racional legal.

A burocratização e a racionalização dos processos na sociedade moderna parecem eliminar a influência da fé e das crenças religiosas na conduta humana. Outro ponto bastante abordado nos estudos organizacionais diz respeito à racionalidade instrumental e a substantiva que derivam dos estudos weberianos.

Ainda nos estudos sobre religião, Pierucci e Prandi (1996) mostram o comportamento da sociedade brasileira, que mesmo convivendo com elementos típicos de uma civilização moderna capitalista, consegue reviver novas religiões e novos deuses que, outrora, sofreram com a dessacralização, devido a um modelo não religioso, expresso por competência profissional, competitividade, autossuficiência e visibilidade social.

Tendo isso em vista, este caso para ensino tem como objetivo voltar a discussão dos estudos organizacionais para as questões relacionadas à religião, à religiosidade e à espiritualidade, tentando identificar nas questões relacionadas à ética e à formação do administrador elementos que demonstrem a forte influência da religião na vida das pessoas e na condução dos grupos. O texto tem por finalidade também levantar questionamentos sobre a influência religiosa no mundo do trabalho e na condução dos negócios a partir de uma leitura que leva em consideração a expressão da religião de um determinado grupo.

\section{A ética protestante e o espírito do capitalismo: a influência de Max Weber no entendimento da ética nos negócios}

Em Weber (2004), a ética protestante é tratada como a percussora de um sistema socioeconômico, em que o trabalho deve ser concebido como vocação, predestinado por Deus, com o objetivo de alcançar a transcendência, mas que, devido à flexibilização de leis, faz desaparecer a ética como um elo evanescente, prevalecendo apenas as características do capitalismo. A influência da religião para ele é nítida na formação de um padrão de comportamento que se transforma na ação do empresário capitalista, o qual substitui a moral religiosa por um cálculo racional de meios e fins para alcançar seus objetivos de lucro.

Uma das principais fontes de onde os preceitos éticos são extraídos é sem dúvida a religião. Ela tem influenciado desde os primórdios indivíduos e grupos em praticamente todas as sociedades existentes. Pelos religiosos de modo geral, pressupõe-se que a vontade divina é pelo menos parcialmente conhecida pelo homem na forma de leis, decretos, mandamentos e ordenamentos, e que devem ser obedecidos durante a vida (Weger \& Oliva, 2005).

A ética é a forma como os indivíduos reagem ao tradicionalmente estabelecido, após julgar as ideias de acordo com seus valores, determinando o que é certo ou errado, permeando apenas as ações livres e conscientes dos indivíduos, não abrangendo as ações tomadas por instinto ou sob fortes pressões (Murguel, Silva, \& Neves, 2006). É o entendimento sobre qual a melhor forma de agir perante uma situação, discernimento e entendimento social sobre o bem e o mal.

De acordo com Toffler (1993), não há um conceito universal sobre o que é ético e o que não é, sobre o que é certo ou errado, apesar de haver uma linha comum entre todas as vertentes. Desse modo, Murguel, Silva e Neves (2006) dita que, pelo ponto de vista fundamentalista, os conceitos éticos não nascem com os seres humanos, e sim são extraídos de fontes exteriores a ele, como ideias adotadas por um grupo, uma pessoa ou uma determinada religião.

As demandas sobre o comportamento ético são, de acordo com Rodrigues (2004), um dos quatro principais quesitos que são necessários para o administrador moderno, junto com: globalização, controle de custos e relações de confiança com os stakeholders. Sendo a responsabilidade corporativa o principal 
desafio das empresas, capaz de redirecioná-las do pensamento de curto prazo, visando apenas à maximização de valor para o acionista através da expropriação de funcionários e clientes, para um pensamento de longo prazo construído em um ambiente menos voltado para o lucro obtido a qualquer custo e com maior ênfase na confiabilidade e em um maior envolvimento afetivo dos indivíduos que influenciam a organização.

A reflexão ética em torno dos assuntos cotidianos sobre os quais o administrador tem que opinar se faz fundamental, para que o mesmo não se torne descomprometido com uma sociedade que cada vez mais se preocupa com a responsabilidade social, tema bastante requisitado pela sociedade atual que preza o cuidado com o meio ambiente, bom tratamento com os funcionários e é avessa ao trabalho escravo e/ou infantil, entre outros (Schroeder, 2004). Em relação ao trabalho escravo, Oliveira, Valadão e Miranda (2013) apresentam um estudo que evidenciam "temas discursivos, discursos e ideologias" através dos "comentários analisados" na imprensa eletrônica nacional, mostrando a verdadeira "importância de compreender a produção intertextual sobre a atuação das corporações" (p. 617). Os autores apresentam as denúncias contra a empresa Zara sobre a utilização de trabalho escravo, no ano de 2011. O bom administrador, o comportamento ético desse profissional é fortemente influenciado por seus professores e pelo corpo diretivo das instituições em que estudou, sendo de fundamental importância que o tema se torne presente durante todo o curso e não apenas em matérias específicas (Schroeder, 2004).

É visceral que os administradores em formação sejam consumidores seletivos dos produtos e serviços oferecidos pelas faculdades, sendo críticos em relação às teorias apresentadas, não sendo apenas consumidores passivos que aceitam sem julgamento o que a indústria da teoria da administração lhes oferece (Micklethwait \& Woolddrige, 2002). Ele deve ser orientado para que não consuma o que de pior oferece a indústria da teoria, essa orientação deve ser sempre voltada para a prática ética (Schroeder, 2004).

\section{A ética capitalista e a formação do jovem executivo}

Tendo esse respaldo ético dos professores e do corpo diretivo da faculdade, deve prevalecer a liberdade de escolha, em que cada um deve refletir de acordo com seus valores e padrões de conduta moral e ética e seguir o caminho que lhe parecer mais adequado, cabendo aos professores o papel de norteadores, e não de formadores de opinião.

As faculdades devem ser imparciais no ensino em qualquer área, deixando que o aluno escolha como atuar e sob quais preceitos éticos, sendo eles religiosos ou não, devendo apresentar um conteúdo laico que não interfira e não conflite com as crenças religiosas dos estudantes.

Giddens (2004) diz que a religião tem perdido força nas últimas décadas, passando a desempenhar um papel menos central na vida social dos homens em virtude do desenvolvimento da ciência e da indústria moderna. Esse fenômeno já era esperado e citado por Weber, Marx e Durkheim, para quem a secularização descreve a perda da influência da religião nas diversas esferas da vida social, e o surgimento de novas facetas e formas da religião adequa-se às exigências do mundo moderno. Apesar disso, grupos protestantes têm conseguido ir contra esse movimento social, e vêm conseguindo aumentar seu número de seguidores no Brasil, inclusive o número de jovens fiéis.

O protestantismo no Brasil iniciou sua história na segunda década do século passado, tendo seu momento de ascensão marcado entre os anos de 1952 e 1962. Nessa época, os protestantes já estavam em sua terceira geração no Brasil, tinham em seu seio jovens burgueses intelectualizados pelo acesso às universidades que surgiram (Mendonça, 2005). O protestantismo chegou ao país principalmente por influência de missões norte-americanas e foi se instalando, moldando-se aos aspectos culturais locais. Reformulado nas últimas décadas pelas igrejas neopentecostais, o protestantismo vem recrutando cada vez mais fiéis no Brasil, sendo considerada, de um modo geral e abrangente, a segunda maior religião em número de fiéis, atrás apenas da Igreja Católica Apostólica Romana. 
Em conjunto com a expansão do protestantismo, veio o reconhecimento no ensino de teologia, fato que possibilitou que diversas vertentes criassem instituições que ensinassem reconhecidamente a teologia (Mendonça, 2005). Após isso, as instituições cresceram e se tornaram faculdades, onde são ofertados os mais variados cursos, dentre eles, o curso de administração.

Nas religiões que seguem o cristianismo, tem-se por pressuposto a crença em um ser supremo, e é obrigatório que os indivíduos tenham um comportamento de índole moral na terra, seguindo os pressupostos bíblicos e os ensinamentos de Jesus, para que seja alcançada a vida além da morte (Giddens, 2004). Porém, esses preceitos muitas vezes são contrários à ética organizacional vigente, colocando os indivíduos em uma encruzilhada moral, entre o que eles devem fazer de acordo com os ensinamentos religiosos, e o que eles devem fazer para permanecerem no emprego, ou ganhar mais dinheiro.

Para Thiry-Cherques (2004), conforme as transformações econômicas e sociais se aceleram, a sociedade passa a conviver em um ambiente de conflitos morais, advindo de um vazio ético que levou a um formalismo sem direção, em que o padrão ético dos executivos mais jovens diverge do padrão médio vigente (Thiry-Cherques, 2004). Ainda segundo autor, o padrão moral característico dos executivos mais moços, diferentemente do que aconteceu com gerações anteriores, possui um caráter antiético, uma vez que seus referenciais e o direcionamento dos demais grupos de executivos que compõem as diversas faixas etárias se mostram incompatíveis (Thiry-Cherques, 2004).

Qualquer que seja a referência ética dos jovens e dos demais executivos, Vergara e Branco (2001) apresentam que as empresas poderão ser julgadas por seus compromissos éticos, pelo foco nas pessoas e pela interação com o ambiente natural. É possível perceber que as ações humanizadas podem ser vistas como fonte de vantagem competitiva, uma vez que, por um lado, os consumidores estão cada vez mais voltados a incorporarem, em suas decisões de consumo, os compromissos éticos, e, por outro, profissionais talentosos sendo atraídos por empresas comprometidas com o desenvolvimento humano e com causas sociais e ambientais (Vergara \& Branco, 2001).

Contudo algumas práticas adotadas por executivos acabam vislumbrando a ausência da ética nas organizações. É o caso do envolvimento da organização com seus stakeholders. Rodrigues (2004) cita o conflito de agência, em que os gerentes, movidos por interesses próprios, assumem decisões que beneficiam a si próprios em detrimento dos acionistas. Como a empresa precisa gerar valor aos mesmos, e pagar altos salários aos executivos, cabe aos stakeholders pagar esses custos.

Outra prática recorrente é o downsizing, em que gerentes, ao buscar poder e retorno financeiro, achatam as estruturas das empresas, expropriando os empregados e deixando-os à deriva, em mercados que dificilmente conseguirão assumir posições equivalentes em outras entidades (Rodrigues, 2004). Ao se defrontar com a ética religiosa nas organizações, o jovem executivo assume uma posição de desconsideração, uma vez que a religião institucionalizada é vista de forma simplória, utilizada como um sistema de enunciados sobre a divindade e sobre a relação com o mundo, incompatíveis com os ideais ético-religiosos e tradicionais, originários da vida familiar (Thiry-Cherques, 2004).

Assim, pode-se afirmar que a ética religiosa está sendo substituída pela ética dos negócios entre os jovens executivos, e o papel da religião é fazer que seus seguidores abandonem os preceitos éticos mundanos e sigam o caminho ético proposto por seus líderes religiosos. Desse modo, pergunta-se: instituições religiosas que oferecem cursos superiores voltados para o mercado de trabalho, como o curso de administração, transmitem um referencial ético-religioso para que os estudantes o sigam depois de formados em sua atuação no mercado ou mantêm a laicidade e a imparcialidade no ensino?

\section{Discussão}

É possível notar diferenças entre os objetivos educacionais da faculdade Cristã (confessional) para outras faculdades (laicas) na formação do gestor de recursos humanos?

RAC, Rio de Janeiro, v. 21, n. 5, pp. 730-742, Setembro/Outubro, 2017, www.anpad.org.br/rac (oc) 
Sim, é perfeitamente visível que a faculdade Cristã preza muito por manter sua cultura ao transmitir o conhecimento para os alunos, buscando sempre conciliar as atividades realizadas na faculdade com as outras atividades da comunidade, como participação dos alunos em ONG's mantidas pela Igreja, palestra de início de período ministrada pelos fundadores da Igreja, entre outras atividades. As faculdades ditas laicas não se esforçam para passar um conteúdo religioso para os alunos.

Referencial-chave: Esta resposta está relacionada à influência da religião no ensino das instituições de ensino. Assim, o referencial-chave encontra-se em: Mendonça (2005); Giddens (2004); e Thiry-Cherques (2004).

Explique como o acúmulo do capital e o cálculo racional de receitas e despesas incentivam os empresários ao Espírito do Capitalismo?

Antes da ética protestante se perder como um elo evanescente, o trabalho era visto como algo predestinado por Deus, como sagrado e como objeto de ascensão. Nesse sentido, a vida dos camponeses, artesãos e pequenos comerciantes pode ser compreendida como ligeiramente simples, em que as principais atividades consistiam em trabalhar, poupar e rezar. Porém, com a flexibilização de leis, toda essa pacata sociedade voltada à salvação é submetida às ações dos grandes empresários, que possuem um único objetivo, o lucro, e para isso, utilizam-se da acumulação do capital e do emprego da contabilidade, surgindo, dessa forma, o espírito do capitalismo.

Hoje percebemos que essa lógica está presente no atual ambiente de negócios, em que gestores ignoram valores, crenças, respeito, e degradam o meio ambiente em busca de seus objetivos de lucro.

Referencial-chave: Este referencial está, sobretudo, relacionado aos estudos de Max Weber em seu livro A Ética Protestante e o Espírito do Capitalismo (Weber, 2004).

Como os aspectos religiosos influenciam a decisão dos gestores?

Os aspectos religiosos influenciam a decisão de gestores através da transferência de preceitos religiosos para a cultura de uma organização, bem como para o julgamento de seus gestores. Estes podem levar em consideração se o comportamento de seus stakeholders condiz com os preceitos de sua religião. Por exemplo, se seus empregados e fornecedores refletem em seus comportamentos, vestígios da religião de seus gestores. Se estes comportamentos forem condizentes com a religião ou a ética empresarial de certos gestores, esses fatores podem ser cruciais para a tomada de decisão durante um processo de recrutamento e seleção.

Referencial-chave: A resposta para esta pergunta reflete o papel influenciador da religião na decisão de gestores. Aqui, ressaltam-se Weber (2004) e Weger e Oliva (2005).

Qual o papel do gestor de recursos humanos ao trabalhar em uma empresa em que as questões religiosas são profundamente consideradas em sua cultura organizacional?

Uma vez que a organização tem uma profunda consideração pela religião em sua cultura, o profissional de recursos humanos deverá estar apto para permear tal condição em suas atividades. Por exemplo, o gestor de RH deverá abordar aspectos religiosos desde o recrutamento e a seleção de colaboradores, passando pelo treinamento, até a criação de projetos e programas sociais enraizados na questão religiosa. De fato, o profissional de recursos humanos não é obrigado a comungar dos mesmos cultos, porém o conhecimento da religião que sustenta a base cultural da organização é de fundamental importância.

Referencial-chave: Esta resposta retrata a religião e seu papel em determinado departamento. Como apresentado, pode ser que o profissional não comungue do mesmo culto, mas o conhecimento religioso torna-se essencial (Giddens, 2004; Thiry-Cherques, 2004; Weger \& Oliva, 2005).

Quando uma empresa contrata uma terceirizada, entende-se que a contratante possui total consciência das atividades realizadas pela contratada. Muitas vezes, casos de exploração de empregados 
nas empresas contratadas são denunciados, e nestas circunstâncias surgem dúvidas sobre quem é (são) o(s) responsável(is) por tais atividades. Quais os motivos que levam empresas a contratarem terceirizadas que utilizam trabalho com condições análogas à escravidão em seu processo produtivo?

Porque além da insaciável sede de lucro e acúmulo de riqueza resultantes de decisões estratégias de mercado, a maioria das organizações abandona em suas decisões o aspecto humano, tanto nos indivíduos que trabalham em uma empresa quanto a despersonificação da empresa, ou seja, cria-se uma entidade chamada pessoa jurídica e atribui-se a ela a responsabilidade sobre essas atividades.

Referencial-chave: Esta resposta traz em sua essência a ética de gestores e, por consequência, a imagem que suas organizações transmitem à sociedade. A ética, neste caso, pode ser formada por uma combinação de valores familiares, aprendidos nas instituições de ensino e também baseada em sua fé (Micklethwait \& Woolddrige, 2002; Thiry-Cherques, 2004; Vergara \& Branco, 2001).

\section{Indicações Bibliográficas}

Giddens, A. (2004). Sociologia. Lisboa: Fundação Calouste Gulbenkian.

Pierucci, A. F., \& Prandi, R. (1996). A realidade social das religiões no Brasil (p. 293). São Paulo: Hucitec.

Weber, M. (2004). A ética protestante e o espírito do capitalismo (p. 335). São Paulo: Companhia das Letras.

\section{Referências}

Giddens, A. (2004). Sociologia. Lisboa: Fundação Calouste Gulbenkian.

Mendonça, A. G. (2005). O protestantismo no Brasil e suas encruzilhadas. Revista USP, 67, 48-67. http://dx.doi.org/10.11606/issn.2316-9036.v0i67p48-67

Micklethwait, J., \& Wooldrige, A. (2002). Os gurus: O que eles dizem, por que é importante e como dar sentido a isso. In J. L. Pierce \& J. W. Newstrom (Eds.), A estante do administrador: Uma coletânea de leituras obrigatórias (5a ed., pp. 26-31). Porto Alegre: Bookman.

Murguel, D. O., Silva, J. da C. O. da, \& Neves, J. M. S. das (2006, outubro). A ética nos negócios como diferencial competitivo. Anais do Encontro Nacional de Engenharia de Produção, Fortaleza, CE, Brasil, 16.

Oliveira, C. R. de, Valadão, V. M., Jr., \& Miranda, R. (2013). Culpada ou inocente? Comentários de internautas sobre crimes corporativos. Revista de Administração de Empresas, 53(6), 617-628. http://dx.doi.org/10.1590/S0034-759020130609

Pierucci, A. F., \& Prandi, R. (1996). A realidade social das religiões no Brasil. São Paulo: Hucitec.

Repórter Brasil. (n.d.). O que é trabalho escravo. Recuperado de http://reporterbrasil.org.br/trabalhoescravo/

Revista de Imprensa Internacional. (2011, agosto 18). Escândalo sobre trabalho escravo atinge Zara no Brasil. Diário de Nótícias, Economia. Recuperado de http://www.dn.pt/economia/interior/escandalo-sobre-trabalho-escravo-atinge-zara-no-brasil1954028.html 
Rodrigues, S. B. (2004). Desafios da administração no século XXI [Edição Especial]. Revista de Administração de Empresas, 44, 108-110. http://dx.doi.org/10.1590/S0034-75902004000500009

Schroeder, I. (2004). A responsabilidade e o desafio na formação ética do administrador. Revista Nacional Angrad, 5(2), 1-9.

Thiry-Cherques, H. R. (2004). O conformismo impaciente: Uma interpretação do quadro de referência ética dos jovens executivos nas organizações brasileiras. Revista de Administração Pública, 38(4), 613-640.

Toffler, B. L. (1993). Ética no trabalho. São Paulo: Makron Books.

Weber, M. (2004). A ética protestante e o espírito do capitalismo. São Paulo: Companhia das Letras.

Weger, M., \& Oliva, F. L. (2005, agosto). O impacto da religião na gestão dos negócios. Anais do SEMEAD - Seminários em Administração, São Paulo, SP, Brasil, 8.

\section{Dados dos Autores}

Éder Júnio de Oliveira

Av. João Naves de Ávila, 2121, 38408-144, Uberlândia, MG, Brasil. E-mail: ederjo16@ gmail.com

João Paulo Henriques Lopes Silva

Av. João Naves de Ávila, 2121, 38408-144, Uberlândia, MG, Brasil. E-mail: jhenriquessilva@ bol.com.br

Murillo César Barbosa dos Santos

Av. João Naves de Ávila, 2121, 38408-144, Uberlândia, MG, Brasil. E-mail: murilloc20@ gmail.com

Rodrigo Miranda

Av. João Naves de Ávila, 2121, 38408-144, Uberlândia, MG, Brasil. E-mail: rodmiranda02@ gmail.com 